\section{Nurturing resilient children}

\author{
Estimulando crianças \\ resilientes
}

"What fascinated me most was how intimate relationships and the desire for being with the other precede the rest of cognitive development, and that this social motivation moves these other achievements forward, including meta-representation and theories about other minds. This intuitive, deeply encoded social orientation is first expressed in the mother's arms and then forms the basis for all future I-Thou relationships."

Donald Cohen, 2001

Resiliency is the term applied to children exposed to psychosocial risk factors, such as poverty and violence, who nevertheless thrive and excel. Threats to the well-being of young children are commonplace throughout the world. ${ }^{1}$ Finding ways to enhance resiliency is a major task for child mental health professionals.

Why are some children more resilient than others, despite shared risk factors? We recall Emmy Werner, a developmental psychologist, who endured World War II as a child. Werner is best known for her longitudinal study of high-risk children born on the Hawaiian Island of Kauai in $1955 .^{2}$ Over the course of 40 years, she traced the course of these children. Some children, despite the odds, managed to succeed. They were often the ones who were fortunate to have, from the beginning, a loving parent or someone outside the family who provided consistent nurturing and support and who served as a positive role model.

Data from selective early intervention programs also indicate that the period surrounding the birth of the infant is critically important and is likely to have enduring behavioral consequences. The scientifically rigorous work of Olds et al. is the most compelling. ${ }^{3}$ Olds has performed a series of clinical trials that compare the outcomes of children born to low-income, unmarried mothers whose families either received a nurse home-visitor during their pregnancy and for the next 24 months or not. By focusing on the mother's psychological, educational and economic needs and the infant's well-being, Olds and his colleagues have demonstrated a number of positive outcomes including a reduced number of subsequent pregnancies, reduced use of welfare, lower rates of child abuse and neglect, and fewer arrests for criminal behavior among the offspring. Although the exact mechanisms by which these effects are achieved remains unknown, these authors argue that one key element is the length of time between the first and second pregnancies by the mothers participating in the home visitation program. This suggests that there was the potential for a greater maternal investment in the children who were in the Nurse Home Visitation Program. Another study performed by the same investigators documented that new mothers visited by nurses had fewer subsequent pregnancies and births (Olds et al., 2004). Remarkably, at 21 months nurse-visited children born to women with low psychological resources were less likely to exhibit language delays, and at 24 months, they exhibited superior mental development to their control-group counterparts. 
What happens in the brains of new parents? Do parents differ depending on their level of investment in the child? James Swain and his colleagues are among the first investigators to analyze the images of the brains of brand new mothers and fathers in response to infant cries and while viewing photographs of their infants. ${ }^{4}$ Not surprisingly, these studies have found that in response to infant cries both fathers and mothers stably activate brain regions involved in auditory processing, empathy and theory of mind. These are some of the same regions activated in romantic love. The response to their own infant's cries extends further to include habit, reward and motivation centers.

Basic molecular studies in animals also point to the importance of this period of life. Michael Meaney et al. have shown that differences in maternal care can dramatically affect a range of outcomes including stress responsivity, anxious behaviors, as well as the female pups' nurturing style when they become new mothers. ${ }^{5}$ These changes appear to be due in part to epigenetic events in the first days of life that can have enduring effects on the level of gene expression. For example, high levels of licking and grooming by the mother can alter in her pups the methylation patterns in the promoter regions of key genes, such as the glucocorticoid receptor in the hippocampus. Consequently, pups born to high licking and grooming mothers show less activation of the hypothalamic-pituitary-adrenal axis in response to stressful stimuli throughout their lives. If this happens in animals, it likely is true of humans as well. If these differences in nurturing affect the expression of the glucocorticoid receptor in the hippocampus and the estrogen receptor in the hypothalamus, there will doubtless be other genes whose expression is also affected.

Hopefully work with animal models will provide new insights on how resiliency is fostered in children by good parenting, and how to identify and treat vulnerable populations. In some ways the focus on the mechanisms by which good parental care induces resiliency is a shift from the more traditional focus on how abuse and neglect leads to psychopathology towards a preventive approach that seeks to foster health rather than to treat pathology.

James $F$ Leckman Yale University, USA

\section{References}

1. Zavaschi ML, Graeff ME, Menegassi MT, Mardini V, Pires DW, Carvalho RH, Rohde LA, Eizirik CL. Adult mood disorders and childhood psychological trauma. Rev Bras Psiquiatr. 2006;28(3):184-90.

2. Werner EE, Smith RS. Overcoming the odds:high risk children from birth to adulthood. Ithaca, NY: Cornell University Press; 1992.

3. Olds DL, Sadler L, Kitzman H. Programs for parents of infants and toddlers: recent evidence from randomized trials. J Child Psychol Psychiatry, in press.

4. Swain JE, Lorberbaum J, Kose S, Strathearn L. Brain basis of early parent-infant interactions: psychology, physiology, and in vivo functional neuroimaging studies. J Child Psychol Psychiatry, in press.

5. Kaffman A, Meaney MJ. Neurodevelopmental sequelae of postnatal maternal care in rodents: clinical and research implications of molecular insights. J Child Psychol Psychiatry, in press. 